\title{
Extended Interfacial Stability Through Simple Acid Rinsing in a Li-rich Oxide Cathode Material
}

Srinivasan Ramakrishnan, ${ }^{a}$ Byungchun Park, ${ }^{\mathrm{a}, \mathrm{b}}$ Jue Wu, ${ }^{\mathrm{c}, \mathrm{d}}$ Wanli Yang, ${ }^{\mathrm{c}}$ Bryan D. McCloskey ${ }^{\mathrm{a}, \mathrm{e} *}$

${ }^{a}$ Department of Chemical and Biomolecular Engineering, University of California Berkeley, Berkeley, CA 94720, USA

${ }^{b}$ LG Chem Research Campus, Battery R\&D, Daejeon, South Korea

${ }^{\mathrm{c} A d v a n c e d ~ L i g h t ~ S o u r c e, ~ L a w r e n c e ~ B e r k e l e y ~ N a t i o n a l ~ L a b o r a t o r y, ~ B e r k e l e y, ~ C A ~ 94720, ~ U S A ~}$

${ }^{\mathrm{d} D e p a r t m e n t}$ of Chemistry, College of Chemistry and Chemical Engineering, Xiamen University,

Xiamen 361005, China

${ }^{\text {e} E n v i r o n m e n t a l ~ E n e r g y ~ T e c h n o l o g i e s ~ D i v i s i o n, ~ L a w r e n c e ~ B e r k e l e y ~ N a t i o n a l ~ L a b o r a t o r y, ~}$ Berkeley, CA 94720, USA

\begin{abstract}
Layered Li-rich Ni, Mn, Co (NMC) oxide cathodes in Li-ion batteries provide high specific capacities $(>250 \mathrm{mAh} / \mathrm{g})$ via O-redox at high voltages. However, associated high-voltage interfacial degradation processes require strategies for effective electrode surface passivation. Here, we show that an acidic surface treatment of a Li-rich NMC layered oxide cathode material leads to a substantial suppression of $\mathrm{CO}_{2}$ and $\mathrm{O}_{2}$ evolution, $\sim 90 \%$ and $\sim 100 \%$ respectively, during the first charge up to $4.8 \mathrm{~V}$ vs. $\mathrm{Li}^{+/ 0}$. $\mathrm{CO}_{2}$ suppression is related to $\mathrm{Li}_{2} \mathrm{CO}_{3}$ removal as well as effective surface passivation against electrolyte degradation. This treatment does not result in any loss of discharge capacity and provides superior long-term cycling and rate performance compared to as-received, untreated materials. We also quantify the extent of lattice oxygen participation in charge compensation ("O-redox") during $\mathrm{Li}^{+}$removal by a novel ex-situ acid titration. Our results indicate that the peroxo-like species resulting from O-redox originate on the surface at least 300 $\mathrm{mV}$ earlier than the activation plateau region around 4.5 V. X-ray photoelectron spectra and Mn$L$ X-ray absorption spectra of the cathode powders reveal a $\mathrm{Li}^{+}$deficiency and a partial reduction of $\mathrm{Mn}$ ions on the surface of the acid-treated material. More interestingly, although the irreversible oxygen evolution is greatly suppressed through the surface treatment, our O K-edge resonant inelastic X-ray scattering shows the lattice O-redox behavior largely sustained. The acidic treatment, therefore, only optimizes the surface of the Li-rich material and almost eliminates the irreversible gas evolution, leading to improved cycling and rate performance. This work therefore
\end{abstract}


presents a simple yet effective approach to passivate cathode surfaces against interfacial instabilities during high-voltage battery operation.

Keywords: Li-ion batteries, Li-rich NMC, Interface passivation, DEMS, OEMS.

\section{BROADER CONTEXT}

The advent of commercial Li-ion batteries in 1991 has since transformed the consumer electronics industry. However, in order to translate these technological advances into large-scale electrification of the transportation sector, significant improvements to battery energy densities are needed. Layered Li-rich Ni, Mn, Co (NMC)-based oxides are promising cathode candidates as they provide high specific capacities $(>250 \mathrm{mAh} / \mathrm{g})$ through the combined participation of transition metals and oxygen anions ("O-redox") in charge compensation during $\mathrm{Li}^{+}$-removal and re-insertion. However, at the high voltages where O-redox is active, degradation processes at the cathode-electrolyte interface result in rapid capacity fade and therefore impede the commercialization of this material. We demonstrate a simple, scalable acid-rinsing procedure for the cathode material, which achieves effective passivation of the cathode surface throughout the voltage window of O-redox, resulting in superior long-term cycling and rate performance. Towards understanding the effect of such treatments on enabling reversible O-redox, we have developed a novel way of quantifying O-redox at various states of charge in such materials using differential electrochemical mass spectrometry.

\section{INTRODUCTION}

A significant boost to the energy density of state-of-the-art Li-ion batteries is needed to hasten the penetration of electric vehicles in the transportation sector. ${ }^{1}$ At the individual cell level, the specific capacity is limited by the layered Li-stoichiometric transition metal oxide cathode of the formula $\mathrm{LiMO}_{2}(\sim 160-180 \mathrm{mAh} / \mathrm{g})$, where $\mathrm{M}=\mathrm{Ni}, \mathrm{Mn}, \mathrm{Co}$ (NMC), compared to the graphite anode's theoretical capacity of $372 \mathrm{mAh} / \mathrm{g} .{ }^{2}$ A related class of materials that offer higher energy density compared to the Li-stoichiometric materials are the Li-rich NMC oxides, $\mathrm{Li}_{1+\mathrm{x}} \mathrm{M}_{1 \text { - }}$ ${ }_{\mathrm{x}} \mathrm{O}_{2}$, where the excess Li resides in the transition metal layer. ${ }^{3,4}$ Specific capacities greater than 250 $\mathrm{mAh} / \mathrm{g}$ can be achieved with these materials. It is believed now that the excess capacity of Li-rich $\mathrm{NMC}$ is derived from the participation of the oxygen anions ("O-redox") in charge compensation, 
starting during the initial charge at high voltages $\left(>4.4 \mathrm{~V} \mathrm{vs.} \mathrm{Li}^{+/ 0}\right)$ beyond the charge compensation provided by transition metal redox. At these high voltages, however, degradation processes at the cathode-electrolyte interface, including surface $\mathrm{O}_{2}$ loss, ${ }^{3,5}$ residual $\mathrm{Li}_{2} \mathrm{CO}_{3}$ decomposition, ${ }^{6}$ and electrolyte decomposition resulting in $\mathrm{CO}_{2}$ evolution, ${ }^{7}$ lead to interfacial impedance increase ${ }^{8}$ and the rapid deterioration of battery performance. As the organic carbonate solvents are stable up to $5 \mathrm{~V}$ vs. $\mathrm{Li}^{+/ 0}$ at an inert electrode, ${ }^{9}$ their degradation during battery operation at high voltages $(>4.4 \mathrm{~V})$ is, therefore, influenced by the chemistry at the cathode surface.

The passivation of the transition metal oxide cathode surface with external coatings of metal oxides, ${ }^{10}$ phosphates ${ }^{11,12}$ and fluorides ${ }^{13-15}$ is a common strategy to confer interfacial (as well as mechanical) stability, ${ }^{16}$ and thus extend the lifetime of batteries. However, with the commonly employed wet-coating methods for the deposition of the coatings, the extent of the coating's coverage on the cathode surface is often non-uniform, which makes the interpretation of the longer-term benefits in terms of battery performance less straightforward. ${ }^{17}$ Additionally, any lattice mismatch between the coating material and the underlying oxide may introduce additional resistances for $\mathrm{Li}^{+}$transport. Layer-by-layer deposition techniques such as atomic layer deposition may be utilized to deposit uniform, well-defined coating layers on the cathode materials in a controlled manner, ${ }^{17-19}$ albeit they are expensive and perhaps not scalable. In addition to these techniques, "reactive" passivation techniques, such as chemical treatments of the electrode surface with reagents such as ammonium carbonate or ammonium sulfate at high temperatures, have been shown to produce $\mathrm{Li}^{+}$-deficient outer layers that result in better rate-capability during cycling. ${ }^{20,21}$ Further, such chemical treatments may reduce surface impurities such as $\mathrm{Li}_{2} \mathrm{CO}_{3}$, which have been shown to decompose in a voltage-dependent manner, leading to the production of $\mathrm{CO}_{2}$ and singlet oxygen, with the latter likely triggering electrolyte degradation leading to increased $\mathrm{CO}_{2}{ }^{6,22-24}$ Therefore, scalable, solution-based passivation methods for the surfaces of high energy cathode materials against interfacial degradation at high voltages are desirable.

For Li-rich NMC oxide materials in the absence of stable passivating layers, O-redox at high states of charge create peroxo-like species that could be susceptible to electrolyte attack. ${ }^{25-27}$ However, the challenges associated with quantifying these species generated at high voltage make it difficult to study their impact on electrolyte degradation. While the reversibility of bulk O-redox over several hundreds of cycles has recently been shown using synchrotron-based X-ray 
spectroscopic techniques such as hard X-ray photoemission ${ }^{28}$ or soft X-ray mapping of resonant inelastic X-ray scattering (mRIXS), ${ }^{29}$ the role of the oxygen redox reactions in affecting interfacial degradation remains unclear.

Quantifying the $\mathrm{CO}_{2}$ and $\mathrm{O}_{2}$ evolved as a function of cell voltage by differential electrochemical mass spectrometry (DEMS) $)^{7,30}$ is a useful in situ technique for studying the various interfacial degradation processes discussed above, such as surface $\mathrm{O}_{2}$ loss and electrolyte decomposition leading to $\mathrm{CO}_{2}$ evolution, as a function of state-of-charge of the materials. Performing these outgassing studies on isotopically enriched cathode materials provides further insight on the origins of the gaseous species, ${ }^{31}$ and therefore informs the design of passivating coatings. DEMS measurements have also been recently extended to quantify ex situ, surface oxygen depletion in Li-stoichiometric NMC 622 materials. $^{32}$

In this work, we present a simple, scalable, solution-based surface passivation method for Li-rich NMC oxide materials via a short air-free chemical treatment with dilute sulfuric acid at room temperature. As determined by DEMS, the acid treatment significantly suppressed first cycle $\mathrm{CO}_{2}$ evolution and eliminated $\mathrm{O}_{2}$ evolution when the Li-rich NMC oxide cathode was delithiated up to $4.8 \mathrm{~V}$ vs. $\mathrm{Li}^{+/ 0}$. Furthermore, no loss in discharge capacity was observed in the acid-treated material as compared to the untreated material. The enhanced interfacial stability in the acidtreated material resulted in superior long-term cycling and improved rate performance. To gain an understanding of the impact of oxygen participation in charge compensation on interfacial reactivity, we use simple methods to fully quantify the peroxo-like species formed during cycling, as well as the evolved $\mathrm{O}_{2}$. Using DEMS in conjunction with ICP-OES, X-ray photoelectron spectroscopy, Mn- $L$ soft X-ray absorption spectroscopy, and O-K mRIXS with both surface- and

bulk-sensitivity, we quantify and compare the various redox processes on the surface as well as in the bulk of the two materials. Our results indicate that the acid treatment only perturbs the surface of the particles, inducing a partial $\mathrm{Li}^{+}$deficiency and a partial reduction of $\mathrm{Mn}^{4+}$ that results in significant improvements to battery performance including gas evolution suppression, enhanced cycle life, and rate capability at high voltage.

\section{RESULTS AND DISCUSSION}

The Li-rich NMC oxide of the stoichiometry, $\mathrm{Li}_{1.16} \mathrm{Ni}_{0.20} \mathrm{Co}_{0.20} \mathrm{Mn}_{0.44} \mathrm{O}_{2}$ ("LR-NMC"), was initially characterized by scanning electron microscopy, powder X-ray diffraction and ICP-OES 
(see experimental section). The residual $\mathrm{Li}_{2} \mathrm{CO}_{3}$ carbonate content on the surface of this material was estimated to be ca. 0.24 wt.\% from titrations against $\mathrm{H}_{2} \mathrm{SO}_{4}$ (Table 1). Electrode preparation and cell assembly were performed in an Argon atmosphere to suppress $\mathrm{Li}_{2} \mathrm{CO}_{3}$ buildup from exposure to ambient moisture and $\mathrm{CO}_{2}$. The as-prepared electrodes were cycled between $4.8 \mathrm{~V}$ (charge cut-off) and $2.5 \mathrm{~V}$ (discharge cut-off) in a hermetically-sealed cell with a Li-foil negative electrode in $1 \mathrm{M} \mathrm{LiPF}_{6}$ in ethylene carbonate-diethyl carbonate (3:7 by volume) electrolyte at a rate corresponding to the removal/insertion of $0.1 \mathrm{Li}^{+}$equivalent in one hour. The headspace of the cell was connected to a custom DEMS setup for outgassing measurements as a function of state-of-charge. For more extensive descriptions of all experimental procedures, see the Experimental Section.

The first cycle voltage profile of this material (Figure 1A, in black) initially shows a sloping region to $\sim 4.4 \mathrm{~V}$, typically associated with transition metal oxidation during $\mathrm{Li}^{+}$removal, followed by a long plateau region typically associated with the activation of the Li-rich $\mathrm{Li}_{2} \mathrm{MnO}_{3}$ phase, wherein the oxygen anions participate in charge compensation and get oxidized. ${ }^{33}$ As typical for this class of materials, there is a large first cycle irreversibility evidenced from the difference between the charge and discharge capacities (Table 1). As a consequence of oxide anion oxidation, ca. $12.7 \mu$ moles $/ \mathrm{g}$ of $\mathrm{O}_{2}$ are evolved during the first charge, as observed in the DEMS measurements (Figure 1A), coincident with the onset of the high voltage plateau. In the same voltage window $\left(\sim 4.4\right.$ to $4.8 \mathrm{~V}$ ) where $\mathrm{O}_{2}$ evolution is observed, there is significant $\mathrm{CO}_{2}$ evolution (32.2 $\mu$ moles $/ \mathrm{g}$ ) from a combination of $\mathrm{Li}_{2} \mathrm{CO}_{3}$ decomposition and electrolyte degradation (vide supra).

To decrease the amount of the residual surface impurities, such as $\mathrm{Li}_{2} \mathrm{CO}_{3}$, on the surface of the Li-rich NMC oxide material, the powder was stirred with $0.1 \mathrm{M} \mathrm{H}_{2} \mathrm{SO}_{4}$ (1:1 LR-NMC: acid weight ratio, or a $\sim 250$-fold molar excess with respect to the $\mathrm{Li}_{2} \mathrm{CO}_{3}$ content) in a $\mathrm{N}_{2}$ atmosphere for about 10 minutes. The acid-treated powder was then rinsed with water and acetone, dried at $135^{\circ} \mathrm{C}$ under vacuum and transferred to an $\mathrm{Ar}$ atmosphere without air exposure. The $\mathrm{Li}_{2} \mathrm{CO}_{3}$ content of the surface-treated sample was reduced to $\sim 0.1 \mathrm{wt} \%$ (Table 1). The surface acidic treatment therefore removed $\sim 58 \%$ of the residual $\mathrm{Li}_{2} \mathrm{CO}_{3}$ on the surface of the cathode particles. As will be discussed later, the oxide surface structure was also beneficially impacted by this acid rinsing procedure. 
Table 1. First cycle specific capacities and gas evolution in the as-received and surface-treated LR-NMC materials (voltage range $=4.8-2.5 \mathrm{~V}$; rate $=0.1 \mathrm{Li}^{+} /$hour).

\begin{tabular}{llcc}
\hline & \multicolumn{2}{c}{ Li-rich NMC Oxide } \\
& & As received & Surface-treated \\
\hline $\mathrm{Li}_{2} \mathrm{CO}_{3}$ content: & wt $\%$ & 0.24 & 0.1 \\
& $\mu \mathrm{moles} / \mathrm{g}$ & 32.5 & 13.5 \\
First cycle $\mathrm{CO}_{2}(\mu \mathrm{moles} / \mathrm{g})$ & 32.2 & 2.4 \\
First cycle $\mathrm{O}_{2}(\mu \mathrm{moles} / \mathrm{g})$ & 12.7 & 0.0 \\
Charge capacity $(\mathrm{mAh} / \mathrm{g})$ & 283 & 242 \\
Discharge capacity $(\mathrm{mAh} / \mathrm{g})$ & 189 & 188 \\
\hline
\end{tabular}

In the charge profile of the surface-treated material (Figure 1A, in red), while the sloping transition metal redox region up to $4.4 \mathrm{~V}$ is similar, the high voltage plateau associated with $\mathrm{O}$ redox is shorter compared to the as-received sample, corresponding to a $40 \mathrm{mAh} / \mathrm{g}$ lower charge capacity, posited to result from a loss of $\mathrm{Li}$ from the Li-excess $\mathrm{Li}_{2} \mathrm{MnO}_{3}$ phase during the surface acidic treatment (vide infra). Notably, there was no difference in the discharge capacity, therefore resulting in a greater first cycle reversibility.

The corresponding outgassing data as a function of voltage show remarkable differences compared to the as-received material (Figure 1, middle and lower panels; in red). Notably, we observe a complete suppression of $\mathrm{O}_{2}$ evolution up to $4.8 \mathrm{~V}$ in the acid-treated material. Coincident with the lack of any $\mathrm{O}_{2}$ release is a significant suppression of $\mathrm{CO}_{2}$ evolution. While $\sim 58 \%$ of the $\mathrm{Li}_{2} \mathrm{CO}_{3}$ on the particle surface was removed by the acid treatment, the suppression in $\mathrm{CO}_{2}$ evolution during the first charge observed in the DEMS experiment is $92 \%$ (Table 1). This observation strongly suggests that, in addition to a reduction in $\mathrm{CO}_{2}$ evolution from $\mathrm{Li}_{2} \mathrm{CO}_{3}$, we achieve a significant degree of interface passivation against electrolyte oxidation in the surfacetreated LR-NMC cathode. We note that a higher amount of $\mathrm{H}_{2}$ evolution is observed in the surfacetreated LR-NMC compared to the as-received material, along with a slight increase in $\mathrm{H}_{2}$ coincident with the onset of the high-voltage plateau in the voltage profile (Figure S1). A possible explanation of this behavior is that $\mathrm{H}^{+}$adsorbed or exchanged with $\mathrm{Li}^{+}$at the LR-NMC particle surface is reduced to $\mathrm{H}_{2}$ in a process coupled to near-surface transition metal reduction (e.g., from the formation of $\mathrm{Mn}^{2+}$, as has been observed at the surface of transition metal oxides after large degrees of delithiation). $\mathrm{H}^{+}$could also desorb or deinsert from the LR-NMC surface and diffuse to the Li metal negative electrode, where it could then evolve $\mathrm{H}_{2}$ from reaction with Li. Research to 
further understand and suppress $\mathrm{H}_{2}$ evolution is currently underway in our laboratory, although we emphasize that the total amount of $\mathrm{H}_{2}$ evolution is small even in our treated particles ( $\left.\sim 25 \mu \mathrm{mol} / \mathrm{g}\right)$, and, as will be shown later, cycling of the treated LR-NMC is substantially improved compared to the untreated LR-NMC.
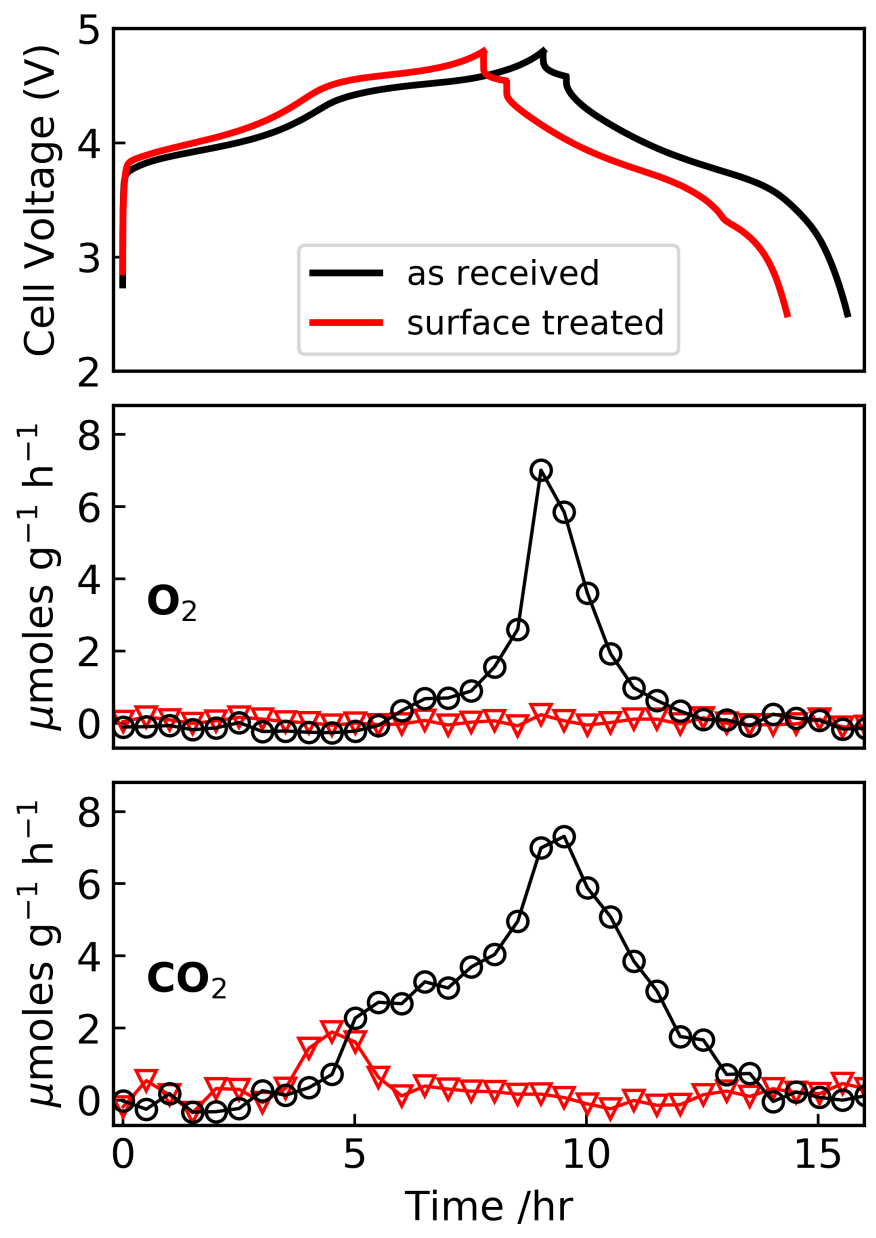

Figure 1. The first cycle charge-discharge profile (top) of the as-received (in black) and surface-treated (in red) LR$\mathrm{NMC}$ cathodes with accompanying $\mathrm{O}_{2}$ and $\mathrm{CO}_{2}$ evolution rates as measured by DEMS (charge/discharge rate $=0.1$ $\mathrm{Li}^{+}$/hour). Total $\mathrm{O}_{2}$ and $\mathrm{CO}_{2}$ evolved and capacities are provided in Table 1.

In order to ascertain whether the improved interfacial stability in the acid-treated materials arises from a possible difference in O-redox behavior, we quantified the extent of O-redox in the two materials as a function of state-of-charge. We performed ex-situ titrations of electrodes charged and discharged to various potentials by immersing them in $3.5 \mathrm{M} \mathrm{H}_{2} \mathrm{SO}_{4}$ in a customdesigned titration cell connected to our DEMS setup (see experimental details). Acid-induced disproportionation of one equivalent of the peroxo-like species in the electrode generated from O- 
redox yields $\mathrm{H}_{2} \mathrm{O}$ and half an equivalent of $\mathrm{O}_{2}$ (equation 1). By measuring this $\mathrm{O}_{2}$ (Figure $\mathrm{S} 2$ ), labelled as QOR-O 2 (where QOR stands for quantifiable O-redox), we precisely quantify the extent of peroxo-like species present at any state of charge in these materials.

$$
\mathrm{O}_{2}^{2-}+2 \mathrm{H}^{+} \rightleftharpoons 1 / 2 \mathrm{O}_{2}+\mathrm{H}_{2} \mathrm{O}
$$

QOR-O ${ }_{2}$, which is directly proportional to the O-redox in the solid material, as a function of the state-of-charge of the cathode materials is shown in Figure 2. We clearly observe higher amounts of QOR-O $\mathrm{O}_{2}$ at the higher cut-off voltages during charging (4.6 and $4.8 \mathrm{~V}$ ) as expected for Li-rich NMC oxides. Noting that transition metal redox in this material can account for roughly $0.4 \mathrm{Li}^{+}$units being extracted $(<4.4 \mathrm{~V})$, we expect that oxidation of the lattice oxygen anions provides charge compensation during Li-removal beyond a capacity of $0.4 \mathrm{Li}^{+}$. For one equivalent of $\mathrm{Li}^{+}$extracted, which is accompanied by a one-electron oxidation of an oxygen anion, half an equivalent of a peroxo-like species will be formed (i.e. $\mathrm{O}^{-}=\frac{1}{2} \mathrm{O}_{2}^{2-}$ ), which after disproportionation, according to equation 1, will evolve $1 / 4$ equivalents of QOR-O 2 . Therefore, for $x$ equivalents of $\mathrm{Li}^{+}$extracted beyond 0.4 , we expect a linear increase in the amount of QOR-O above $4.4 \mathrm{~V}$ based on equation 2. For $x>0.4$ in Fig. 2, the QOR-O 2 values show reasonable

$$
\frac{\text { mol QOR- } \mathrm{O}_{2}}{\text { mol cathode }}=\frac{x-0.4}{4} \times 100
$$

agreement with, although are slightly lower than, the predicted QOR-O 2 values based on the expected value provided in equation 2 (which is shown as a dashed line in Fig. 2A and B). The small difference between the measured QOR-O $\mathrm{O}_{2}$ and the predicted QOR-O $\mathrm{O}_{2}$ value from equation 2 is roughly equal to the amounts of $\mathrm{O}_{2}$ and $\mathrm{CO}_{2}$ evolved during battery cycling (Figure 1), 0.11 and $0.28 \mathrm{~mol} \%$ respectively. Therefore, these ex-situ electrode titrations coupled with in-situ DEMS gas evolution enable the complete quantification of O-redox and parasitic electrochemical outgassing processes.

Interestingly, even in the cathode charged to $4.2 \mathrm{~V}(x<0.4$, where the high voltage plateau region has not been reached), we observed a significant amount of QOR-O $\mathrm{O}_{2}$ on acid addition (Figure 2A, inset), implying the presence of O-redox at much lower potentials than the plateau region typically observed during charging in these Li-rich materials. We also extended the ex-situ 
titrations to quantify the degree of reversibility of O-redox after full charge-discharge cycles to various charge potential cutoffs (Figure 2, solid points). The charged electrodes were discharged down to a cut-off voltage of $2.8 \mathrm{~V}$ to prevent any reduction of the evolved $\mathrm{O}_{2}$, which in carbonatebased electrolytes would result in substantial electrolyte degradation. ${ }^{30}$ For the electrodes charged to 4.2 and $4.4 \mathrm{~V}$, the amount of QOR- $\mathrm{O}_{2}$ after the subsequent discharge to $2.8 \mathrm{~V}$ approaches zero, implying there is good reversibility of O-redox at these low voltages. However, for the electrodes charged to $4.6 \mathrm{~V}$ and $4.8 \mathrm{~V}$, i.e., beyond the voltage plateau in Figure 1 (and $x>0.4$ ), ca. $5-10 \%$ of the total peroxo-like species formed during charge are not reduced back to $\mathrm{O}^{2-}$ (based on equation 1), implying a slight loss in the reversibility of O-redox after the $1^{\text {st }}$ discharge. Of note, the quantity of peroxo-like species that remain after the first cycle are an order of magnitude greater than the $\mathrm{O}_{2}$ evolved during electrochemical cycling $(0.1 \mathrm{~mol} \%$, Figure 1$)$, which implies that factors other than surface $\mathrm{O}_{2}$ loss during cycling are responsible for the loss of reversibility of $\mathrm{O}$ redox after the first cycle. Decreasing the discharge cut-off to $2 \mathrm{~V}$ did not affect the reduction of these residual peroxo-like species.

In contrast to the as-received material, ex-situ titrations of the surface-treated material (Figure 2B) reveal a negligible amount of QOR- $\mathrm{O}_{2}$ in the electrode charged to $4.2 \mathrm{~V}$, and much lower QOR- $\mathrm{O}_{2}$ in the electrode charged to $4.4 \mathrm{~V}$ (Figure 2B inset). Electrodes charged to $4.6 \mathrm{~V}$ and $4.8 \mathrm{~V}$ show amounts of QOR-O $\mathrm{O}_{2}$ comparable to the as-received material; this measured Oredox above $0.4 \mathrm{Li}^{+}$extraction is consistent with the amount expected if O-redox accounted for all charge compensation during delithiation (dashed line in Fig. 2B, equation 2). The lower amounts of these species in the acid-treated materials at low states of charge points to $\mathrm{Li}^{+}$deficiency on the particle surface (vide infra). Upon discharge to $2.8 \mathrm{~V}$ after a charge up to $4.8 \mathrm{~V}$, roughly the same $5-10 \%$ peroxo-like species remain unreduced as compared to the pristine sample, suggesting that the surface treatment has no effect on the overall reversibility of bulk O-redox. 

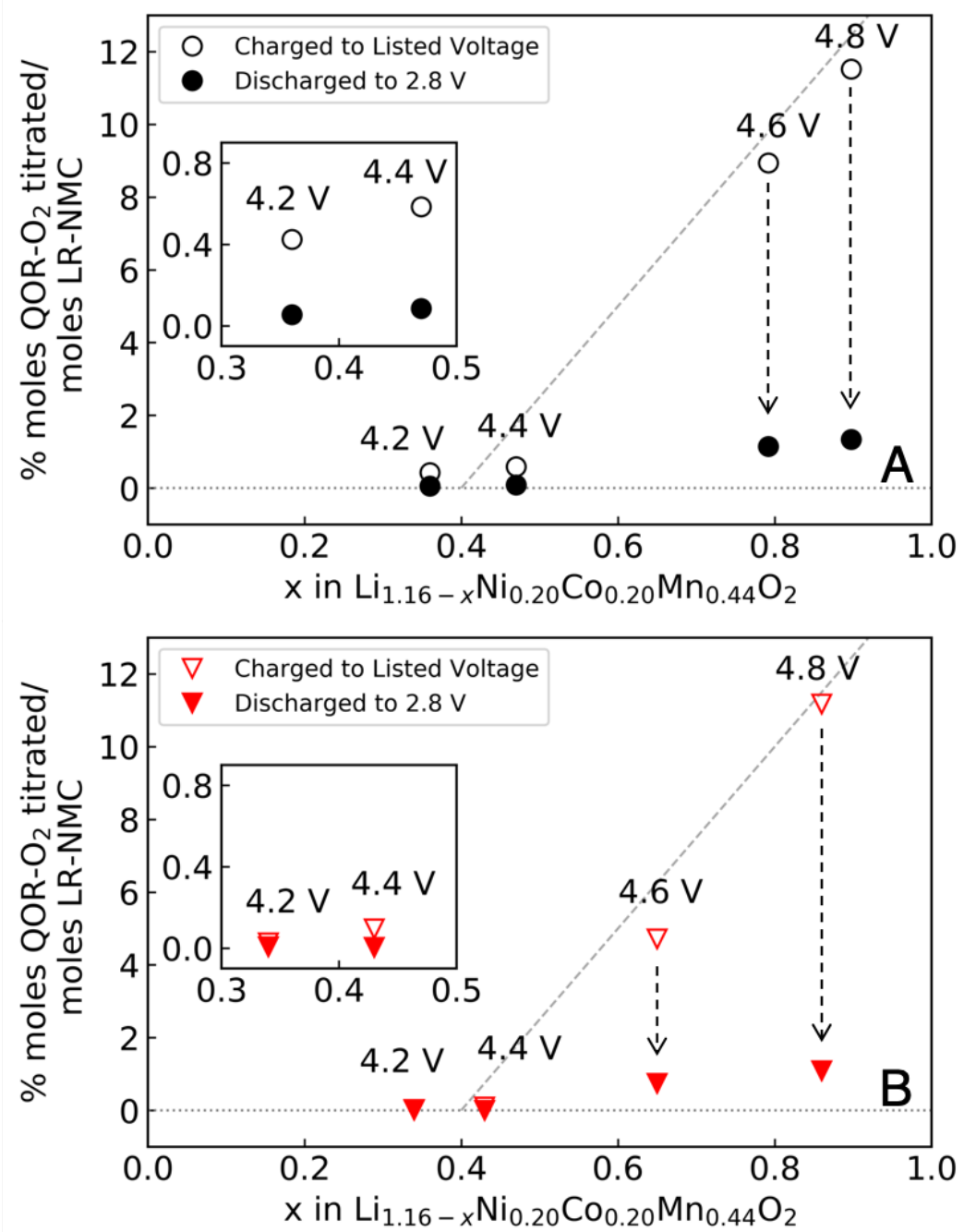

Figure 2. Ex-situ titrations to quantify O-redox $\left(\mathrm{QOR}-\mathrm{O}_{2}\right)$ of electrodes charged to various potentials (as indicated) and discharged to $2.8 \mathrm{~V}$, for the (A) as-received (black) and (B) surface-treated (red) LR-NMC oxide cathodes. The sloped dashed line is the QOR-O $\mathrm{O}_{2}$ expected on charge if O-redox accounted for $100 \%$ of charge compensation beyond $\mathrm{x}=0.4$ (see equation 2). Transition metal redox is expected to account for most of the charge compensation when $\mathrm{x}<0.4$, although modest amounts of QOR-O 2 are observed even in this region (insets).

We clearly observe lower amounts of peroxo-like species at lower states of charge $(x<0.5)$ in the acid treated material compared to the as-received material (Figure 2). As the acidic treatment is expected to perturb only the surface of the cathode particles, this result implies that O-redox during charge mainly originates at the particle surface and migrates inward with increasing delithiation. To probe the distribution and evolution of the peroxo-like species during delithiation as a function of particle depth in the cathode materials, we isotopically labeled the particle surface of the as-received material with ${ }^{18} \mathrm{O}_{2}$ (see experimental section). Using this ${ }^{18} \mathrm{O}$ labeling procedure, 
the NMC particles are not uniformly enriched with ${ }^{18} \mathrm{O}$ throughout their bulk, and instead exhibit a strong ${ }^{18} \mathrm{O}$ gradient very near the surface of the particle, with the bulk of the particle lattice still being natural abundance labeled (dominantly ${ }^{16} \mathrm{O}$ ). Although we have not quantified the relative ${ }^{18} \mathrm{O} /{ }^{16} \mathrm{O}$ gradient near the particle surface, we use this strategy here to show qualitatively that the O-redox originates at the particle surface at low states of charge and progresses into the particle bulk with continued delithiation.

Table 2. Extent of ${ }^{18} \mathrm{O}$-enrichment of the evolved $\mathrm{CO}_{2}$ and $\mathrm{O}_{2}$ during acid titrations of the as-received powder and cycled electrodes prepared from the ${ }^{18} \mathrm{O}$-enriched as received LR-NMC material. $\mathrm{CO}_{2}$ is evolved from surface carbonates present as impurities on the powder, and $\mathrm{O}_{2}$ is evolved from peroxo-like species formed due to lattice oxidation during $\mathrm{Li}^{+}$removal. $\mathrm{No} \mathrm{O}_{2}$ evolved during the acid titration of the as received powder.

\begin{tabular}{|c|c|c|c|c|}
\hline \multicolumn{2}{|c|}{${ }^{18}$ O-enriched LR-NMC Powder } & \multicolumn{3}{|c|}{${ }^{18}$ O-enriched LR-NMC Electrodes } \\
\hline & & & $\begin{array}{l}\text { Charged } \\
\text { to } 4.4 \mathrm{~V}\end{array}$ & $\begin{array}{c}\text { Charged } \\
\text { to } 4.8 \mathrm{~V}\end{array}$ \\
\hline$\% \mathrm{C}^{16,18} \mathrm{O}_{2} /$ total $\mathrm{CO}_{2}$ (titrated) & 37 & $\%{ }^{16,18} \mathrm{O}_{2} /$ total $\mathrm{O}_{2}$ (titrated) & 32 & 9 \\
\hline$\% \mathrm{C}^{18,18} \mathrm{O}_{2} /$ total $\mathrm{CO}_{2}$ (titrated) & 11 & $\%{ }^{18,18} \mathrm{O}_{2} /$ total $\mathrm{O}_{2}($ titrated $)$ & 10 & 1 \\
\hline$\% \mathrm{C}^{16,16} \mathrm{O}_{2} /$ total $\mathrm{CO}_{2}($ titrated $)$ & 52 & $\%{ }^{16,16} \mathrm{O}_{2} /$ total $\mathrm{O}_{2}($ titrated $)$ & 58 & 90 \\
\hline
\end{tabular}

The extent of ${ }^{18} \mathrm{O}$ surface enrichment was approximated from the relative ratios of $\mathrm{C}^{16,16} \mathrm{O}_{2}$, $\mathrm{C}^{16,18} \mathrm{O}_{2}$ and $\mathrm{C}^{18,18} \mathrm{O}_{2}$ evolved from the residual $\mathrm{Li}_{2} \mathrm{CO}_{3}$ on the surface of the powders on the addition of $10 \mathrm{M} \mathrm{H}_{2} \mathrm{SO}_{4}$ (Figure S3), assuming that the oxide surface was enriched to a similar extent, as was shown for Ni-rich NMC materials previously. ${ }^{32}$ Of the total $\mathrm{CO}_{2}$ evolved, 37\% was the singly labeled $\mathrm{C}^{16,18} \mathrm{O}_{2}, 11 \%$ the doubly labeled $\mathrm{C}^{18,18} \mathrm{O}_{2}$, with the rest (52\%) being unlabeled $\mathrm{C}^{16,16} \mathrm{O}_{2}$ (Table 2). The electrodes prepared from the ${ }^{18} \mathrm{O}$-labeled powder were charged to $4.4 \mathrm{~V}$ and $4.8 \mathrm{~V}$, which correspond to voltage cutoffs where a small and large amount of O-redox was observed (Figure 2A), respectively, and then harvested for ex-situ acid titrations as described above. The percent ratio of ${ }^{16,18} \mathrm{O}_{2},{ }^{18,18} \mathrm{O}_{2}$, and ${ }^{16,16} \mathrm{O}_{2}$ evolved from the titration of the electrode charged to $4.4 \mathrm{~V}$ (Figure S4A) were ca. 32\%, 10\%, and 58\%, respectively, which roughly matched the enrichment ratio of the surface $\mathrm{Li}_{2} \mathrm{CO}_{3}$ on the labeled LR-NMC powder (Table 2). From this isotopic distribution, we conclude that the peroxo-like species generated from O-redox at lower potentials $(\leq 4.4 \mathrm{~V})$ originate near the particle surface. The corresponding distribution of $\mathrm{O}_{2}$ evolved from the titration of the electrode charged to $4.8 \mathrm{~V}$ (Figure S4B) were ca. 9\%, 1\%, and $90 \%$, implying that at the high state of charge $(4.8 \mathrm{~V})$, the majority of the peroxo-like species are present, not surprisingly, in the particle bulk. Hence, we conclude that the O-redox originates at 
the particle surface at $\sim 4.2 \mathrm{~V}$ vs $\mathrm{Li} / \mathrm{Li}^{+}$and penetrates into the particle bulk with increasing delithiation. Also of note is that the $\mathrm{O}_{2}$ released during charging of the ${ }^{18} \mathrm{O}$ enriched material has an isotopic distribution that matches the surface carbonate (Figure S5 and Table S1), indicating that any $\mathrm{O}_{2}$ released during delithiation occurs from the particle surface and not the particle bulk.

We also estimated the amount of carbonate species on the electrode surface, viz., the residual $\mathrm{Li}_{2} \mathrm{CO}_{3}$, as well as newly formed carbonate species from electrolyte decomposition, by measuring the amount of $\mathrm{CO}_{2}$ evolved during the ex-situ acid titrations (which we define as SC$\mathrm{CO}_{2}$, derived from total surface carbonates (SC)) of electrodes extracted from cells after being charged to various potentials $\left(4.2-4.8 \mathrm{~V}\right.$ vs. $\left.\mathrm{Li}^{+/ 0}\right)$. The amount of $\mathrm{SC}-\mathrm{CO}_{2}$ corresponding to the total amount of native $\mathrm{Li}_{2} \mathrm{CO}_{3}$ on the cathode material prior to cell assembly (Table 1), is marked by the dashed lines for the as-received and surface-treated LR-NMC materials (Figure 3). After charging to $4.8 \mathrm{~V}$, the total amount of SC- $\mathrm{CO}_{2}$ titrated $(\sim 80 \mu \mathrm{mol} / \mathrm{g})$ from the as received electrode is quite high considering that the electrodes were thoroughly rinsed in dimethyl carbonate and dried, suggesting that these decomposition products strongly adhere to the electrode surface. Similar to the increasing amount of $\mathrm{CO}_{2}$ evolved during charging as a function of voltage (Figure 1A, black), the as-received Li-rich NMC oxide material shows an increase in surface carbonate deposits as a function of state-of-charge in the ex-situ titrations (Figure 3), implying a corresponding increase in electrolyte degradation. The surface-treated materials, however, show much lower $\mathrm{SC}-\mathrm{CO}_{2}$ at all potentials compared to the as received material. Notably, there is a negligible increase in $\mathrm{SC}-\mathrm{CO}_{2}$ from $4.2 \mathrm{~V}$ to $4.4 \mathrm{~V}$, whereas the as-received LR-NMC shows a 3fold increase in the same voltage window. Overall, it is clear from the outgassing analysis during cell cycling (Figure 1) and the solid carbonate deposition analysis in Figure 3 that the acid surface treatment suppresses interfacial degradation at all potentials. As the bulk O-redox behavior is unchanged upon acid treatment, evidenced by the similar amounts of QOR-O $\mathrm{O}_{2}$ evolved in the two samples at high states of charge (vide supra), changes on the surface of the cathode are very likely responsible for the large suppression of outgassing seen in Figures 1 and 3. As compared to the asreceived LR-NMC, the lower amount of the peroxo-like species detected in the surface-treated samples charged to $4.4 \mathrm{~V}$ (Figure 2B, inset) may be responsible for the enhanced interfacial stability of the treated materials, as the peroxo-like species in this range clearly originate from the particle surface (Figure S4A, Table 2). 


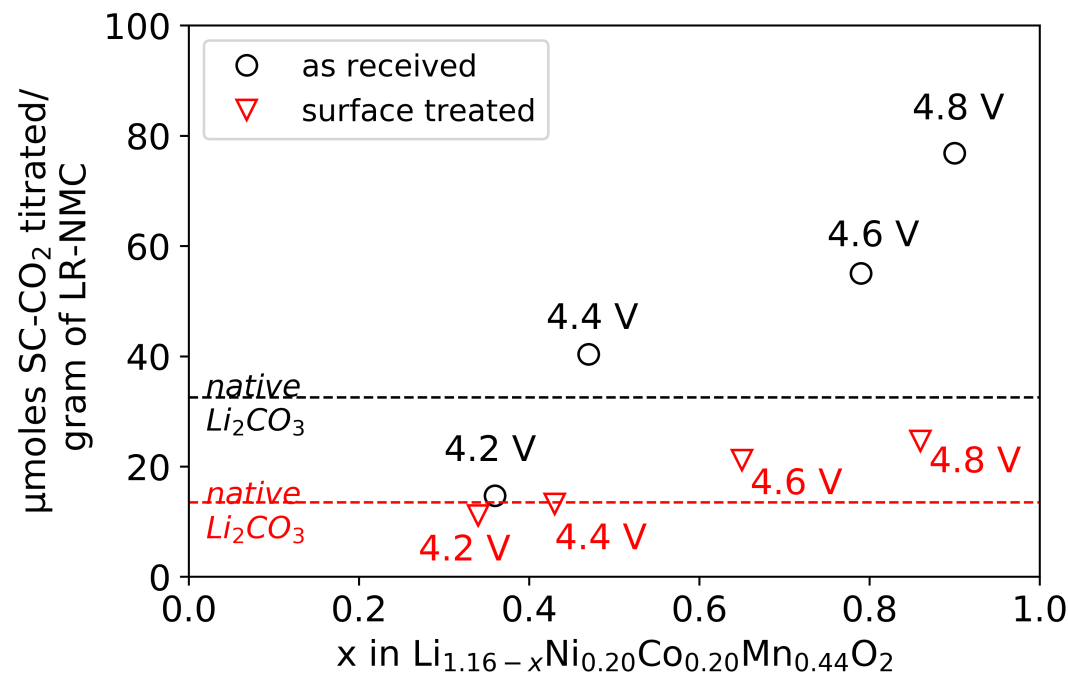

Figure 3. $\mathrm{SC}-\mathrm{CO}_{2}$ from surface-bound carbonate species during ex-situ titrations of charged electrodes (voltages as indicated).

To probe the chemical structure of the particle surfaces, we perform X-ray photoelectron spectroscopy of the untreated and surface-treated Li-rich NMC oxide powders, which reveal several differences in the Li 1s, O 1s and Mn 2p spectra, as shown in Figure 4A-C. The Li 1s spectrum (Figure 4A) of the as-received sample consists of a major peak centered at $53.9 \mathrm{eV}$ assigned to the lithiated transition metal oxide, and a small shoulder centered around $55.4 \mathrm{eV}$ assigned to $\mathrm{Li}_{2} \mathrm{CO}_{3} .{ }^{34}$ In the surface-treated powder, the peak corresponding to the lithium in the transition metal oxide is of reduced intensity, which provides evidence for a partial $\mathrm{Li}^{+}$loss from the outer surface upon acidic treatment. Concomitant with this surface depletion of $\mathrm{Li}^{+}$, the $\mathrm{O} 1 \mathrm{~s}$ peak of the transition metal oxide, centered at $529.1 \mathrm{eV}$ in the pristine sample, shifts to a more positive binding energy by ca. $0.4 \mathrm{eV}$ upon acidic treatment (Figure 4B), possibly from an undercoordination of the oxygen anions, and is of reduced intensity. The $\mathrm{O} 1 \mathrm{~s}$ peak at $531.5 \mathrm{eV}$, assigned to $\mathrm{Li}_{2} \mathrm{CO}_{3}$, is also of reduced intensity in the surface-treated powder. In the $\mathrm{Mn} 2 \mathrm{p}$ spectrum (Figure 4C) of the surface-treated powder, there is a slight average reductive shift of both the Mn 2p $\mathrm{p}_{1 / 2}$ and $\mathrm{Mn} 2 \mathrm{p}_{3 / 2}$ features compared to the as-received powder. The Ni $2 \mathrm{p}$ and Co $2 \mathrm{p}$ spectra in both materials were similar (Figure S6). These results, therefore, suggest that the $\mathrm{Li}^{+}$ loss from the outer LR-NMC surface during acid treatment, presumably as $\mathrm{Li}_{2} \mathrm{O}$ given the negligible XPS spectra intensity changes of the transition metals, originates from the Li-excess $\mathrm{Li}_{2} \mathrm{MnO}_{3}$ phase. 
In the powder XRD studies of the pristine and surface-treated materials (Figure S7), we observed the growth of a small peak near the (003) reflection at $19^{\circ}$, which is related to an expansion of the c-axis due to surface $\mathrm{Li}^{+}$removal. $\mathrm{A} \sim 10 \%$ loss of $\mathrm{Li}^{+}$in the surface-treated material with no change in stoichiometry of the transition metals was confirmed by ICP-OES analysis of the two materials. The lower $\mathrm{Li}^{+}$in the treated material is, therefore, in agreement with the Li 1s XPS results, as well as with the observed lower first cycle charge capacity compared to the as-received material.
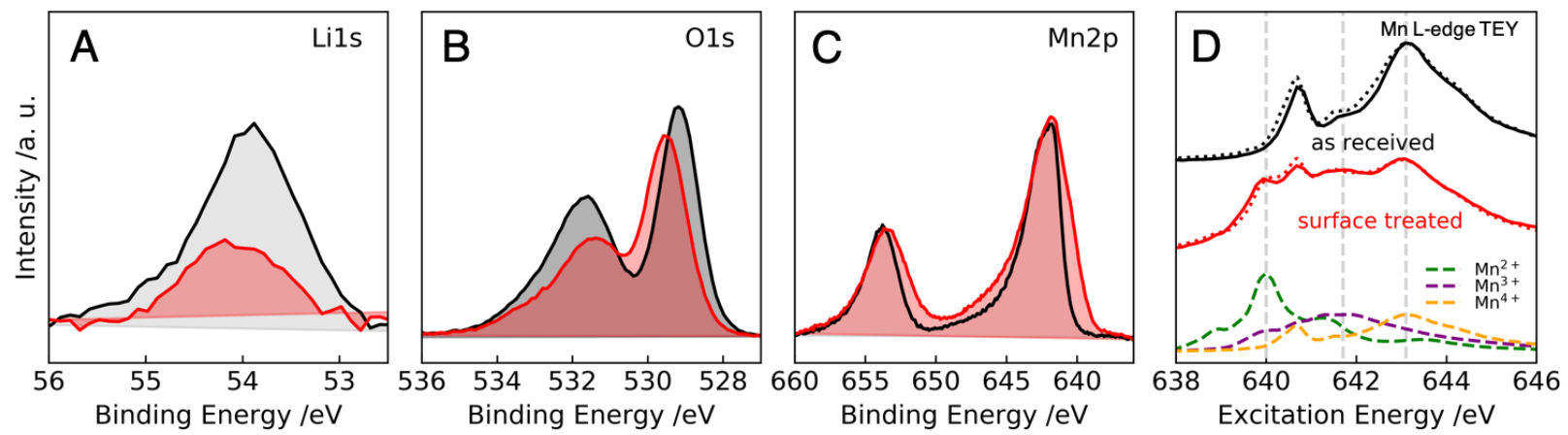

Figure 4. A) Li 1s, B) O 1s, C) Mn 2p XPS spectra and D) Mn L-edge sXAS spectra in the TEY mode (dotted lines are the fits based on the constituent $\mathrm{Mn}^{2+}, \mathrm{Mn}^{3+}$ and $\mathrm{Mn}^{4+}$ spectra (dashed lines)) of the as-received (in black) and acid treated (in red) LR-NMC oxide powders.

While the small shift in Mn $2 p$ XPS implies the reduction of Mn on the surface, a more direct probe of the Mn $3 d$ valence states is needed to clarify and quantify the Mn states. It is known that soft X-ray absorption spectra (sXAS) of TM L-edges provide a much more direct probe of the Mn $3 d$ valence states instead of the small chemical potential shift in XPS. ${ }^{35}$ Furthermore, quantifications of L-edge sXAS could provide detailed results of Mn oxidation states due to the direct sensitivity of Mn- $L$ sXAS to Mn $3 d$ valence states. ${ }^{36}$ As shown in Figure $4 \mathrm{D}$, the Mn L-edge spectra collected through the surface-sensitive total electron yield (TEY) channel reveals distinct lineshapes between the materials with and without the acid-treatment. In particular, the growth of the absorption peaks at $641.8 \mathrm{eV}$ and $640 \mathrm{eV}$ corresponds directly to the increased contents of $\mathrm{Mn}^{3+}$ and $\mathrm{Mn}^{2+}$ states, respectively, as shown by the reference spectra on the bottom of Figure 4D. ${ }^{37}$ The dramatic change of the Mn- $L$ sXAS lineshape allows a simple linear combination fitting of the experimental data by using the reference spectra, which precisely fits the spectra and extracts the quantified values of Mn oxidation states. ${ }^{38}$ Our fittings (dotted lines in Figure 4D) find roughly 
$35 \%$ of $\mathrm{Mn}^{3+}$ and $15 \%$ of $\mathrm{Mn}^{2+}$ on the surface of the acid-treated sample, sharply contrasting the dominating $\mathrm{Mn}^{4+}$ surface in the as received sample.

Another important question is whether the lattice oxygen redox activities are affected by the surface modification discussed above. We thus further performed O K-edge spectroscopy in different modes. The O-K sXAS displays a typical broadening around the so-called "pre-edge" features between 528-533 eV range in the charged states, which could be seen in both systems (Figure S8). As we have recently clarified, such a O-K pre-edge evolution is dominated by the increased TM-O hybridization in the oxidized (charged) state and is not a signature of oxygen redox. ${ }^{39}$ In the meantime, recent studies have established the tool-of-choice for probing the lattice (non-released) oxygen redox behavior through mRIXS, which further resolves the sXAS fluorescence yield signals along a completely new dimension called emission energy (horizontal axis of Figure 5). Specifically, a feature typically at $523.7 \mathrm{eV}$ emission energy emerges and disappears upon electrochemical cycling, ${ }^{29}$ fingerprinting the oxygen redox states. ${ }^{39}$ As shown in Figures 5B and 5E, both systems show clear signature of lattice oxygen redox, with the oxidized oxygen mRIXS feature at $523.7 \mathrm{eV}$ emission energy emerges in the charged state (indicated by the white arrows) and disappears when the electrodes are discharged (Figures 5C and 5F). These results are consistent with those presented in Figure 2, where the oxygen redox is directly quantified, although the small amount of peroxo-like species that persist after a full 4.8-2.8 V cycle, as shown in Figure 2, do not appear to be captured in the analogous mRIXS maps in Figure $5 \mathrm{C}$ and $\mathrm{F}$. We note that the peroxo-like species after a full cycle only account for only $\sim 1 \mathrm{~mol} \%$ of the total oxygen content, which may define the limits of detection for the mRIXS. These findings are critical because the surface treatment significantly reduces the gas evolution (Figure 1), however, has essentially no impact on the lattice oxygen redox. 


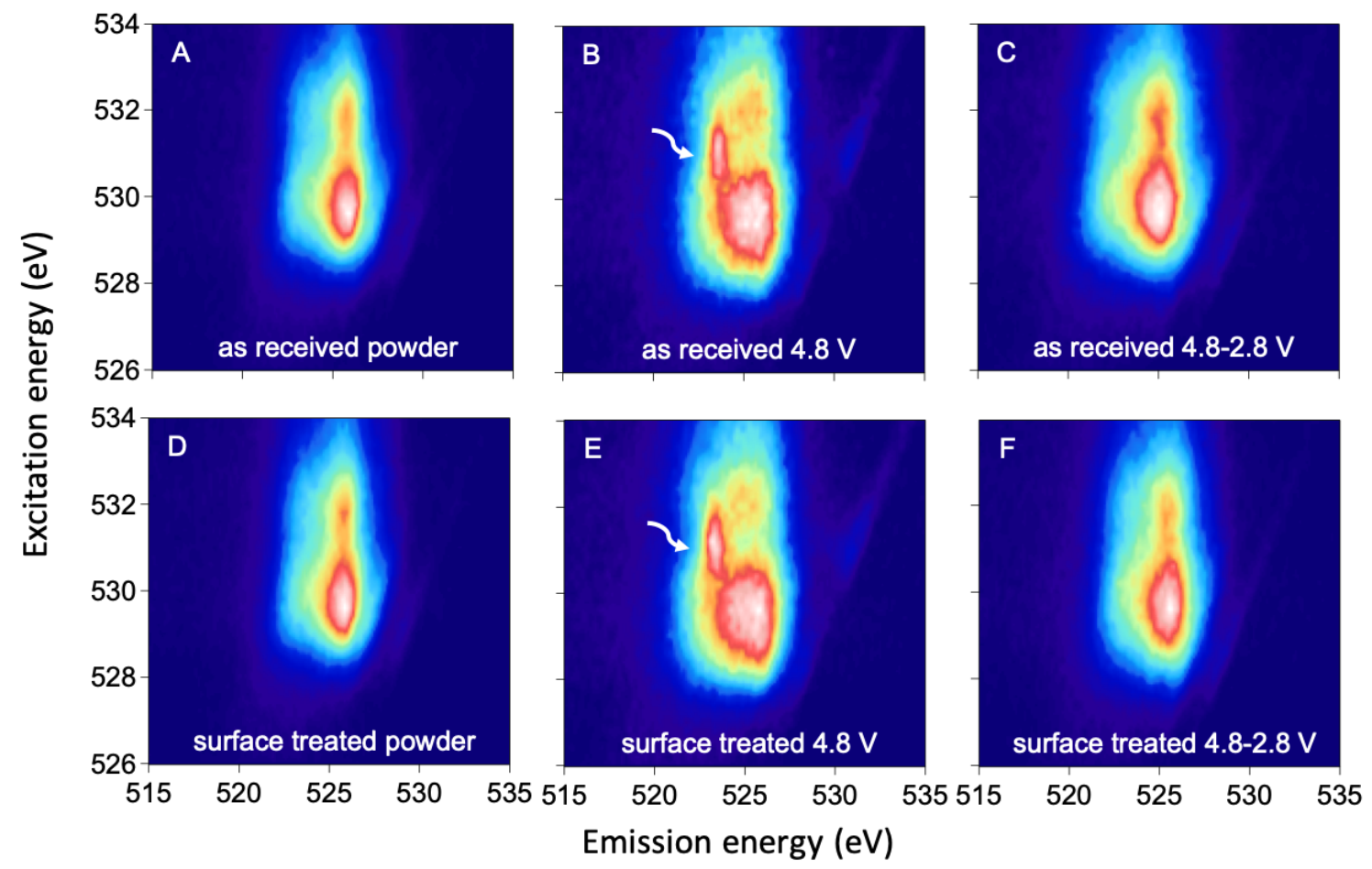

Figure 5. O K-edge RIXS map of the as-received (A to C) and surface-treated (D to F) LR-NMC oxide powders and cathodes.

The suppression of first cycle interfacial degradation evidenced by the lack of $\mathrm{O}_{2}$ and $\mathrm{CO}_{2}$ evolution in our DEMS results also led to extendable stability during cycling (Figure 6A) in a coincell versus a Li-foil anode. In the as-received material, there is a seeming increase in discharge capacity during cycling, which we ascribe to parasitic electrochemical processes such as electrolyte decomposition on the cathode surface, which eventually leads to premature cell failure (Figure 1B). There is also a modest difference in the rate capability of the two materials when cycled at rates increasing from $\mathrm{C} / 10$ to $1 \mathrm{C}$ (Figure $6 \mathrm{~B}$ ), where $\mathrm{C}$ represents the current needed to a complete discharge of all reversible capacity in 1 hour (i.e., $30.5 \mathrm{~mA} / \mathrm{g}$ ). The as-received material is unable to recover its low rate discharge capacity after high rate operation (between $1 \mathrm{C}$ and 0.1 $\mathrm{C}$ ), and this capacity further fades rapidly with increasing cycles at $0.1 \mathrm{C}$. The surface-treated material on the other hand, recovers the initial discharge capacity after high rate cycling followed by a very gradual loss in discharge capacity, akin to the cycling data at $0.1 \mathrm{C}$ in Figure 6A. The corresponding average voltage fade of the surface-treated NMC material is expectedly similar to the as-received material (Figure S9). We hypothesize that the interfacial degradation processes in the as-received sample, evidenced from our DEMS results, are accelerated during fast cycling, 
leading to irreversible changes to the electrode material resulting in a rapid capacity fade. The reduction in interfacial reactivity with the surface treatment, therefore, significantly impacts cathodic stability for long-term battery performance as well as higher rate cycling.
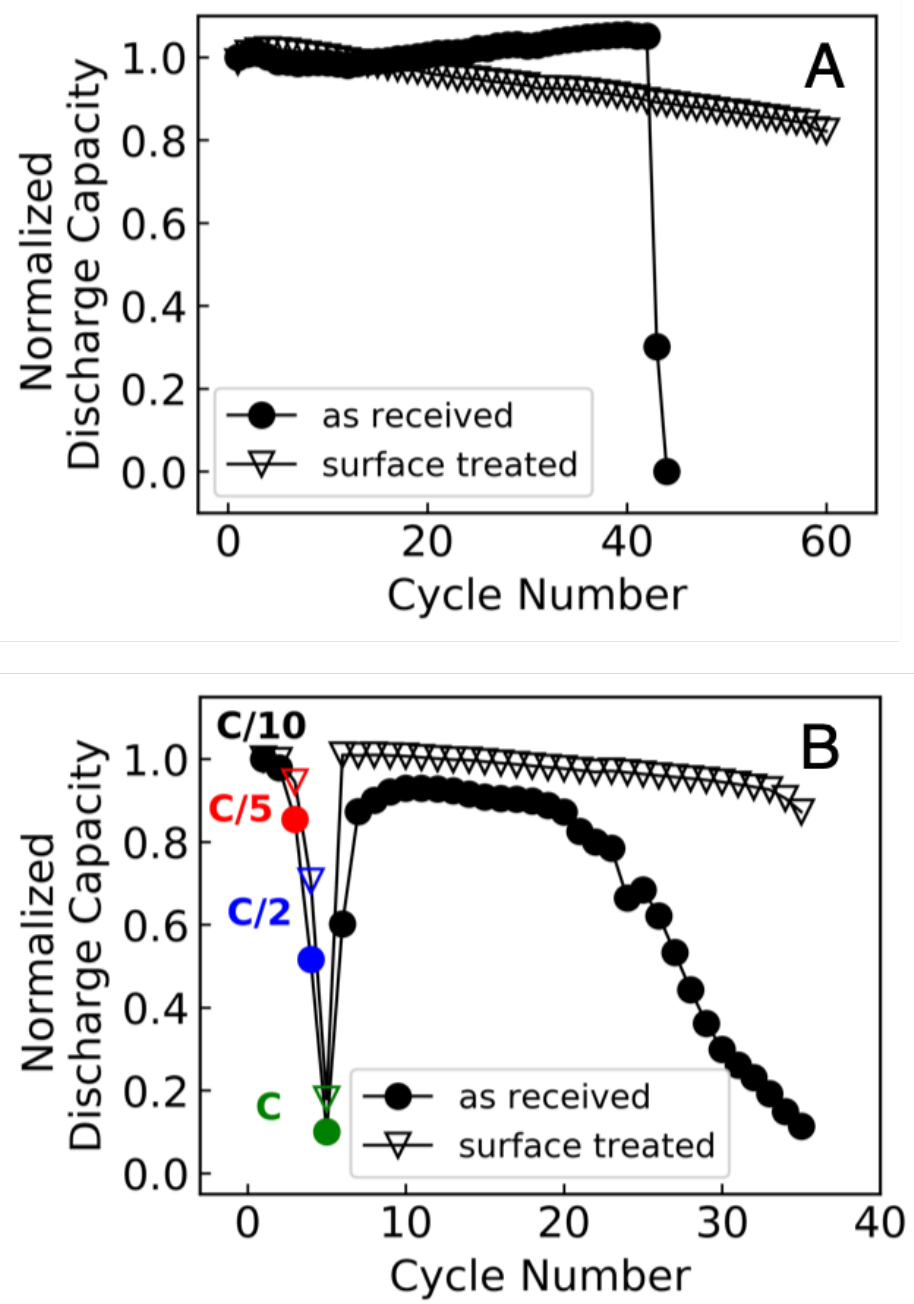

Figure 6. (A) Long term cycling performance of the materials in a coin cell (rate $=0.1 \mathrm{Li}^{+} / \mathrm{hour}$, or $30.5 \mathrm{~mA} / \mathrm{g}$ ); (B) rate capability tested in a coin cell at various rates shown (a rate of $\mathrm{C}$ corresponds to a complete discharge in one hour).

\section{CONCLUSIONS}

In this work we have described a simple solution-based, inexpensive and scalable method for passivating the surface of Li-rich NMC oxide cathode materials against interfacial degradation during high-voltage cycling. We observe significantly lower first-cycle outgassing in the treated electrodes, which leads to improved rate and long-term cycling performance. Ex-situ titrations, 
employed to fully quantify peroxo-like species, along with spectroscopic studies indicate that only

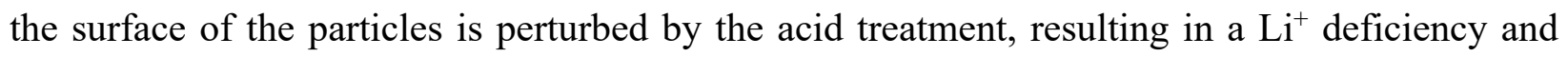
partially reduced $\mathrm{Mn}$. The bulk lattice oxygen redox reaction is largely preserved although the gas evolution is significantly reduced through the surface treatment, indicating that $\mathrm{O}_{2}$ release occurs only from oxide anion oxidation at the particle surface and not the particle bulk; ${ }^{18} \mathrm{O}$ isotopic labeling also confirms that $\mathrm{O}_{2}$ is only evolved from the particle surface. Extending this surface modification procedure to other high-voltage cathode materials that exhibit interfacial instabilities would be a valuable strategy to improve material lifetime, particularly at high degrees of delithiation needed to enable higher energy densities in $\mathrm{Li}$-ion batteries.

\section{EXPERIMENTAL DETAILS}

Surface Acidic Treatment: The Li-rich NMC oxide powder, as received from LG Chem, was stirred with $0.1 \mathrm{M} \mathrm{H}_{2} \mathrm{SO}_{4}$ (1:1 by weight) for ten minutes in a round bottomed flask attached to a Schlenk setup under $\mathrm{N}_{2}$ (no air-exposure). The contents were transferred to a Schlenk air free filter (Chemglass Co.) under $\mathrm{N}_{2}$, rinsed with $20 \mathrm{ml}$ de-ionized water three times, followed by $20 \mathrm{ml}$ of acetone. The rinsed powder was dried under vacuum for an hour, and then transferred to a preheated antechamber of the glove box (Ar atmosphere), where it was subsequently dried for two days at $135^{\circ} \mathrm{C}$ under vacuum.

Electrode Preparation: All the electrodes for battery cycling were prepared inside an Ar glovebox and never exposed to ambient atmosphere. A slurry of the Li-rich NMC oxide powder, polyvinylidene difluoride (Sigma-Aldrich) binder and carbon black (90:5:5 weight ratio) in Nmethylpyrolidine (Sigma-Aldrich) was homogenized at $5000 \mathrm{rpm}$ in a Thinky ${ }^{\mathrm{TM}}$ planetary mixer. The slurry was then cast on pre-weighed stainless steel meshes (Dutch twill weave \#200x600, 60 $\mu \mathrm{m}$ pore size) of $12 \mathrm{~mm}$ diameter, and dried at $135^{\circ} \mathrm{C}$ under vacuum overnight. The porosity of the as-prepared electrodes was calculated to be ca. $55 \%$. The ${ }^{18} \mathrm{O}$-enrichment method is described in previous publications. ${ }^{6,32}$

Battery Assembly and DEMS: The batteries were assembled in a custom designed hermetically sealed cell fitted with gas capillaries to sample the gases evolved during battery cycling. A $11 \mathrm{~mm}$

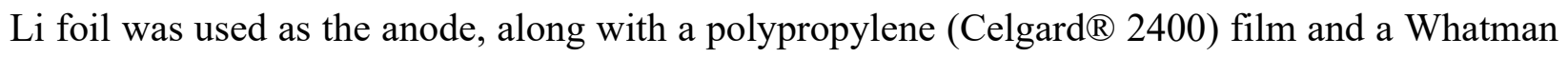


glass fiber separator. The separators, each $12 \mathrm{~mm}$ in diameter. were punched outside the glove box, washed in soap water followed by rinsing with de-ionized water, isopropanol and acetone, and dried at $120^{\circ} \mathrm{C} .80 \mu \mathrm{L}$ of a $1 \mathrm{M}$ solution of $\mathrm{LiPF}_{6}$ (Sigma Aldrich Co.) in EC-DEC (BASF), dried with $3 \AA$ molecular sieves, was used as the electrolyte. The batteries were charged and discharged at a rate of $0.1 \mathrm{Li}^{+}$/hour unless otherwise noted, with a BioLogic VSP potentiostat. The DEMS setup is described in previous publications. ${ }^{30,41}$ Gases from the headspace of the batteries were sampled and fed to the mass spectrometer. The detected $\mathrm{CO}_{2}(\mathrm{M} / \mathrm{Z} 44)$ and $\mathrm{O}_{2}(\mathrm{M} / \mathrm{Z}$ 32) were quantified based on calibrations of the ion currents in the mass spectrometry data with known amounts of reference gases.

For the ex-situ titrations, the electrodes, after charging/discharging to a designated stateof-charge, were disassembled from the cell inside the glove box, rinsed several times with dimethyl carbonate (BASF) and dried at $100^{\circ} \mathrm{C}$ overnight under vacuum in the glove box antechamber. The dried electrodes were then weighed out in the glove box in a custom-designed, air-tight cell fitted with capillaries and a septum seal ${ }^{32}$ for subsequent acid addition. After the addition of $3.5 \mathrm{M} \mathrm{H}_{2} \mathrm{SO}_{4}$ to the sealed cell connected to the DEMS system, the M/Z 32 and M/Z 44 signals measured were then used to determine $\mathrm{QOR}-\mathrm{O}_{2}$ and $\mathrm{SC}-\mathrm{CO}_{2}$ respectively. The uncertainties in the determination

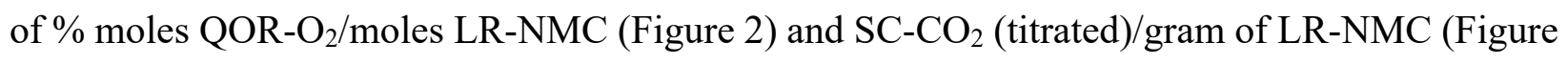
3 ) were \pm 0.08 (\% units) and \pm 5 ( $\mu$ moles/g units) respectively.

Coin Cell Assembly and Testing: For longer term cycling and rate studies, the electrodes prepared on SS meshes described above were assembled in CR2032 coin cells (MTI) with a Li metal counter electrode (18 mm diameter), polypropylene (Celgard $\left.{ }^{\circledR} 2400\right)$ and Whatman glass fiber separators, and $1 \mathrm{M} \mathrm{LiPF}_{6}$ in EC-DEC (3:7), and cycled using a Bio-Logic VMP3 potentiostat.

Materials Characterization. SEM images of the as-received and surface-treated powders were collected on a Zeiss Gemini Ultra-55 Analytical Scanning Electron Microscope with an in-built EDX detector for elemental analysis. Both the as-received LR-NMC as well as the surface treated powders are composed of $\sim 10 \mu \mathrm{m}$ sized secondary particles containing smaller $\sim 200 \mathrm{~nm}$ primary particles (Figure S10). EDX measurements indicate a uniform spatial distribution of Ni, Mn, Co and $\mathrm{O}$ atoms at different length scales (Figure S11-S13). XRD measurements were made on a 
Bruker D2-Phaser $(\mathrm{Cu} \mathrm{K} \alpha)$. The XPS spectra were measured on a Thermo Fischer K-Alpha Plus system at the Molecular Foundry at the Lawrence Berkeley National Laboratory.

Synchrotron sXAS and mRIXS measurements. The soft X-ray spectroscopy measurements were performed in the iRIXS endstation at Beamline 8.0.1 of Advanced Light Source (ALS) in Lawrence Berkeley National Laboratory (LBNL) ${ }^{42}$ The coin-type cells with different states of charges were disassembled and the electrodes were rinsed with dimethyl carbonate to remove the residual salt/electrolyte immediately after cycling to lock the SOC. The harvested electrodes were loaded into a holder in the Ar-filled glove box and transferred into ultrahigh vacuum chamber via homemade suitcase to avoid any air exposure. The sXAS signals were collected from the side of electrode facing the current collector in both TEY and TFY modes. The quantitative fitting of Mn$L$ spectra is detailed in previously published work. ${ }^{36} \mathrm{O}$ K-edge mRIXS data were collected by through the ultrahigh efficiency modular soft X-ray spectrometer. ${ }^{43}$ We have noticed that radiation damage could lead to the disappearance of the key oxygen redox feature. ${ }^{44}$ Therefore, in order to reduce the radiation damage issue and collect the signals over a large number of active material particle, the samples were kept moving throughout the mRIXS measurements. Final 2D images were obtained via a multi-step data processing including background subtraction, time and beam flux normalization, elastic calibration and so on. ${ }^{29,45}$

\section{ASSOCIATED CONTENT}

Supporting Information

Electronic Supplementary Information (ESI) is available at pubs.rsc.org.

\section{AUTHOR INFORMATION}

Corresponding Author

bmcclosk@berkeley.edu

\section{Notes}

The authors declare no competing financial interests.

\section{ACKNOWLEDGEMENTS}


This work was supported by LG Chem grant \#043001. The authors would like to thank Kyle Diederichsen for assistance with ICP-OES measurements, and Sara Renfrew for insightful discussions. The soft X-ray spectroscopy used resources of the Advanced Light Source, which is a DOE Office of Science User Facility under contract no. DE-AC02-05CH11231.

\section{REFERENCES}

1 D. Andre, S. J. Kim, P. Lamp, S. F. Lux, F. Maglia, O. Paschos and B. Stiaszny, J. Mater. Chem. A, 2015, 3, 6709-6732.

2 A. Manthiram, ACS Cent. Sci., 2017, 3, 1063-1069.

3 E. M. Erickson, F. Schipper, T. R. Penki, J.-Y. Shin, C. Erk, F.-F. Chesneau, B. Markovsky and D. Aurbach, J. Electrochem. Soc., 2017, 164, A6341-A6348.

$4 \quad$ G. Assat and J.-M. Tarascon, Nat. Energy, 2018, 3, 373-386.

$5 \quad$ P. Rozier and J. M. Tarascon, J. Electrochem. Soc., 2015, 162, A2490-A2499.

6 S. E. Renfrew and B. D. McCloskey, J. Am. Chem. Soc., 2017, 139, 17853-17860.

7 B. Strehle, K. Kleiner, R. Jung, F. Chesneau, M. Mendez, H. A. Gasteiger and M. Piana, J. Electrochem. Soc., 2017, 164, A400-A406.

8 M. Gauthier, T. J. Carney, A. Grimaud, L. Giordano, N. Pour, H.-H. Chang, D. P. Fenning, S. F. Lux, O. Paschos, C. Bauer, F. Maglia, S. Lupart, P. Lamp and Y. Shao-Horn, J. Phys. Chem. Lett., 2015, 6, 46534672.

9 R. Imhof and P. Novak, J. Electrochem. Soc., 1999, 146, 1702.

10 Y.-K. Sun, M.-J. Lee, C. S. Yoon, J. Hassoun, K. Amine and B. Scrosati, Adv. Mater., 2012, 24, 1192-1196.

11 S. H. Lee, B. K. Koo, J. C. Kim and K. M. Kim, J. Power Sources, 2008, 184, 276-283.

12 S.-H. Kang and M. M. Thackeray, Electrochem. commun., 2009, 11, 748-751.

13 J. Zheng, M. Gu, J. Xiao, B. J. Polzin, P. Yan, X. Chen, C. Wang and J. G. Zhang, Chem. Mater., 2014, 26, 6320-6327.

14 J. M. Zheng, Z. R. Zhang, X. B. Wu, Z. X. Dong, Z. Zhu and Y. Yang, J. Electrochem. Soc., 2008, 155, A775.

15 Y. K. Sun, M. J. Lee, C. S. Yoon, J. Hassoun, K. Amine and B. Scrosati, Adv. Mater., 2012, 24, 1192-1196.

16 J. Cho, Y. J. Kim, T.-J. Kim and B. Park, Angew. Chemie Int. Ed., 2001, 40, 3367-3369.

17 Z. Chen, Y. Qin, K. Amine and Y. K. Sun, J. Mater. Chem., 2010, 20, 7606-7612.

18 J. Xie, A. D. Sendek, E. D. Cubuk, X. Zhang, Z. Lu, Y. Gong, T. Wu, F. Shi, W. Liu, E. J. Reed and Y. Cui, ACS Nano, 2017, 11, 7019-7027.

19 J. H. Woo, J. J. Travis, S. M. George and S.-H. Lee, J. Electrochem. Soc., 2015, 162, A344-A349.

20 B. Qiu, M. Zhang, L. Wu, J. Wang, Y. Xia, D. Qian, H. Liu, S. Hy, Y. Chen, K. An, Y. Zhu, Z. Liu and Y. S. Meng, Nat. Commun., , DOI:10.1038/ncomms12108.

D. Y. W. Yu, K. Yanagida and H. Nakamura, J. Electrochem. Soc., 2010, 157, A1177.

N. Mahne, S. E. Renfrew, B. D. McCloskey and S. A. Freunberger, Angew. Chemie Int. Ed., 2018, 57, 5529-5533.

23 J. Wandt, A. T. S. Freiberg, A. Ogrodnik and H. A. Gasteiger, Mater. Today, 2018, 21, 825-833.

24 T. Hatsukade, A. Schiele, P. Hartmann, T. Brezesinski and J. Janek, ACS Appl. Mater. Interfaces, 2018, 10, 38892-38899.

M. Saubanère, E. McCalla, J. M. Tarascon and M. L. Doublet, Energy Environ. Sci., 2016, 9, 984-991.

E. McCalla, A. M. Abakumov, M. Saubanere, D. Foix, E. J. Berg, G. Rousse, M.-L. Doublet, D. Gonbeau, P. Novak, G. Van Tendeloo, R. Dominko and J.-M. Tarascon, Science (80-. )., 2015, 350, 1516-1521. Z. Chen, J. Li and X. C. Zeng, J. Am. Chem. Soc., 2019, 141, 10751-10759. G. Assat, A. Iadecola, D. Foix, R. Dedryvère and J.-M. Tarascon, ACS Energy Lett., 2018, 3, 2721-2728. K. Dai, J. Wu, Z. Zhuo, Q. Li, S. Sallis, J. Mao, G. Ai, C. Sun, Z. Li, W. E. Gent, W. C. Chueh, Y. Chuang, R. Zeng, Z. Shen, F. Pan, S. Yan, L. F. J. Piper, Z. Hussain, G. Liu and W. Yang, Joule, 2019, 3, 518-541.

30 B. D. McCloskey, D. S. Bethune, R. M. Shelby, G. Girishkumar and A. C. Luntz, J. Phys. Chem. Lett., 2011, 2, 1161-1166.

31 K. Luo, M. R. Roberts, R. Hao, N. Guerrini, D. M. Pickup, Y. S. Liu, K. Edström, J. Guo, A. V. Chadwick, 
L. C. Duda and P. G. Bruce, Nat. Chem., 2016, 8, 684-691.

32

33

34

S. E. Renfrew and B. D. McCloskey, ACS Appl. Energy Mater., 2019, 2, 3762-3772.

J. R. Croy, M. Balasubramanian, K. G. Gallagher and A. K. Burrell, Acc. Chem. Res., 2015, 48, 2813-2821. K. N. Wood and G. Teeter, ACS Appl. Energy Mater., 2018, 1, 4493-4504.

W. Yang, X. Liu, R. Qiao, P. Olalde-Velasco, J. D. Spear, L. Roseguo, J. X. Pepper, Y. Chuang, J. D. Denlinger and Z. Hussain, J. Electron Spectros. Relat. Phenomena, 2013, 190, 64-74.

Q. Li, R. Qiao, L. A. Wray, J. Chen, Z. Zhuo, Y. Chen, S. Yan, F. Pan, Z. Hussain and W. Yang, J. Phys. D. Appl. Phys., 2016, 49, 413003.

R. Qiao, T. Chin, S. J. Harris, S. Yan and W. Yang, Curr. Appl. Phys., 2013, 13, 544-548.

R. Qiao, K. Dai, J. Mao, T.-C. Weng, D. Sokaras, D. Nordlund, X. Song, V. S. Battaglia, Z. Hussain, G. Liu and W. Yang, Nano Energy, 2015, 16, 186-195.

W. Yang and T. P. Devereaux, J. Power Sources, 2018, 389, 188-197.

W. Yang, Nat. Energy, 2018, 3, 619-620.

B. D. McCloskey, D. S. Bethune, R. M. Shelby, T. Mori, R. Scheffler, A. Speidel, M. Sherwood and A. C. Luntz, J. Phys. Chem. Lett., 2012, 3, 3043-3047.

R. Qiao, Q. Li, Z. Zhuo, S. Sallis, O. Fuchs, M. Blum, L. Weinhardt, C. Heske, J. Pepper, M. Jones, A.

Brown, A. Spucces, K. Chow, B. Smith, P.-A. Glans, Y. Chen, S. Yan, F. Pan, L. F. J. Piper, J. Denlinger, J. Guo, Z. Hussain, Y.-D. Chuang and W. Yang, Rev. Sci. Instrum., 2017, 88, 033106.

Y.-D. Chuang, Y.-C. Shao, A. Cruz, K. Hanzel, A. Brown, A. Frano, R. Qiao, B. Smith, E. Domning, S.-W. Huang, L. A. Wray, W.-S. Lee, Z.-X. Shen, T. P. Devereaux, J.-W. Chiou, W.-F. Pong, V. V. Yashchuk, E. Gullikson, R. Reininger, W. Yang, J. Guo, R. Duarte and Z. Hussain, Rev. Sci. Instrum., 2017, 88, 013110. Z. W. Lebens-Higgins, J. Vinckeviciute, J. Wu, N. V. Faenza, Y. Li, S. Sallis, N. Pereira, Y. S. Meng, G. G. Amatucci, A. Van Der Ven, W. Yang and L. F. J. Piper, J. Phys. Chem. C, 2019, 123, 13201-13207.

J. Wu, S. Sallis, R. Qiao, Q. Li, Z. Zhuo, K. Dai, Z. Guo and W. Yang, J. Vis. Exp., 2018, 49, 413003. 